Gazi University
Journal of Science
$\mathrm{http} / /$ dergipark.gov.tr/gujs

\title{
Simultaneous Effect of Suction and Cavity for Controlling Flow Separation on NACA 0012 Airfoil - CFD Approach
}

\author{
Esmaeel FATAHIAN (D), Hossein FATAHIAN* \\ Department of Mechanical Engineering, Nour Branch, Islamic Azad University, Nour, Iran
}

Highlights

- This research focuses on simultaneous effect of cavity and suction on flow separation control.

- Present flow control method indicates a significant impact on enhancing aerodynamic performance.

- Stall angle has increased from $14^{\circ}$ to $22^{\circ}$ and the flow separation has been delayed.

\begin{tabular}{l} 
Article Info \\
\hline \\
Received: $18 / 05 / 2020$ \\
Accepted: $15 / 07 / 2020$ \\
Keywords \\
\hline Suction \\
Flow separation \\
Cavity \\
Lift coefficient \\
Drag coefficient
\end{tabular}

\section{INTRODUCTION}

Recently, many studies on aerodynamic analysis of airfoil have been performed numerically and experimentally. Computational Fluid Dynamics (CFD) has now found its place among experimental and analytical methods for analyzing fluid flow, heat transfer and diverse problems [1-5], and the use of this method for engineering analysis has become more common. The boundary layer causes many problems for design in most areas of fluid mechanics. The methods developed for managing boundary layer, or to increase lift force and decrease drag force, are known as boundary layer control or flow control. The purpose of flow control is to achieve more lift force and less drag force in airfoil, and finally to increase the aerodynamic performance with the increment of lift to drag ratio. Airfoil is one of the geometries used in various industries. Analyzing the flow around airfoils is of great importance in helicopter rotors, aircraft maneuvers, ships, the automotive industry, tower design, and turbomachines. Flow separation on a wing during flight causes to decrease lift and increases the drag force which can threaten the efficiency and stability of the aircraft [6]. Also, in aerospace and aviation investigations, the flow separation results in generating noise. Hence, flow control systems are required for overcoming such difficulties. The flow separation control techniques have been considered as a significant field of fluid mechanics [7-10]. The flow separation control can be achieved employing active methods for example; blowing and suction jets [11-14], and synthetic jet actuators [15-17], or passive methods such as flap, slat, vortex generator, and Gurney flap [18-21]. Flow simulation around the airfoil up to pre-stall and stall range continues to be a challenging problem and requires experimental results to determine the actual behavior of the flow. Since 
experimental tests, especially in the case of complex geometries and high Reynolds number flow, are very expensive and have limitations, researchers are focusing on efficient numerical methods to achieve acceptable results at a lower cost and closer to experimental results. Many notable researches were reported to analyze flow separation and control it by utilizing active and passive systems [22-24]. Besides, several efforts have been done on the aerodynamic characteristic of the airfoil with cavity [25-28]. De Gregori and Fraioli [29] experimentally studied the airfoil having a cavity on the airfoil. Vuddagiri et al. [30] numerically studied the fluid flow of an airfoil having circular cavities at three different locations of the airfoil. The elliptical cavity indicated more appropriate results than the others. Ma et al. [31] analyzed the impacts of suction on airfoil aerodynamic performance. They found that the suction has a better control effect as the suction holes are located near the separation point. Genc et al. [32] implemented the active flow control techniques over the airfoil in a transient condition numerically. They found that the suction flow control gave the best results. Yousefi et al. [33] numerically investigated jet width impact of suction and blowing systems on an airfoil. They concluded that lift to drag ratio enhanced by increasing jet width of suction. Zhang et al. [34] numerically studied the applying of a suction method to postpone the flow separation on the airfoil. The changes in consuming energy were computationally analyzed during this process. Lei et al. [35] implemented the suction method in the laminar flow over the airfoil. They stated that their flow control system could prevent generating flow separation. Zhou et al. [36] examined the Mach number impact of an airfoil for controlling the flow separation utilizing a small plate. They stated that an appropriate aerodynamic performance was obtained.

Until now, there is no numerical study that investigates the effect of simultaneous suction and cavity on controlling and delaying the flow separation on the NACA 0012 airfoil. Furthermore, a special attempt is done to numerically analyze the aerodynamic performance of airfoil through CFD technique using simultaneous suction and cavity. The flow over the airfoil is computationally analyzed by URANS solver for unsteady flow condition and a detailed flow consideration have been reported. The present CFD results provide a practical reference for designing the flow control systems.

\section{COMPUTATIONAL DOMAIN}

The computational domain and a C-type structured grid are depicted in Figure 1. The computational domain is extended from 10c upstream to $20 \mathrm{c}$ downstream. Also, upper boundary and lower boundary are extended $10 \mathrm{c}$ from the profile. Figure 2 illustrates the grid closer view for baseline airfoil and airfoil with suction and cavity. In Figure 3, boundary condition of velocity inlet is considered at inlet boundary, upper boundary and lower boundary. No-slip wall condition is imposed on the surface of airfoil. Also, the boundary condition of pressure outlet is used at the outlet and boundary condition of velocity inlet is set at jet location. Three different computational domains with $8 \mathrm{c}, 10 \mathrm{c}$, and $12 \mathrm{c}$ upstream to $16 \mathrm{c}, 20 \mathrm{c}$, and $24 \mathrm{c}$ downstream from the airfoil are generated to analyze pressure coefficient $\left(C_{P}\right)$ for domain extent independence test (Figure 4). This test is carried out at $\mathrm{Re}=5 \times 10^{5}$ and $\alpha=14^{\circ}$. From this figure, the domain with 10c upstream and 20c downstream is appropriate for simulation. 


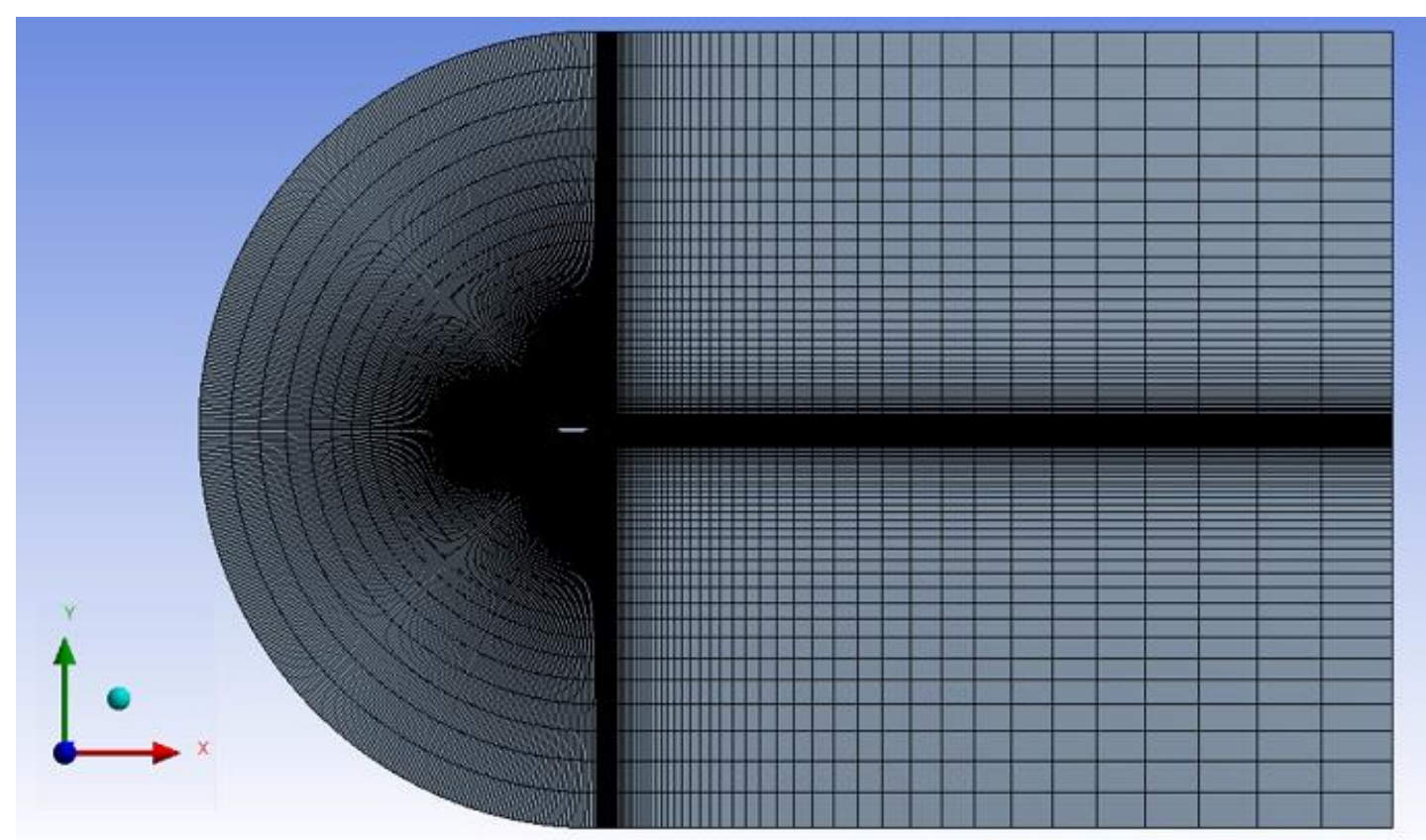

Figure 1. Computational domain

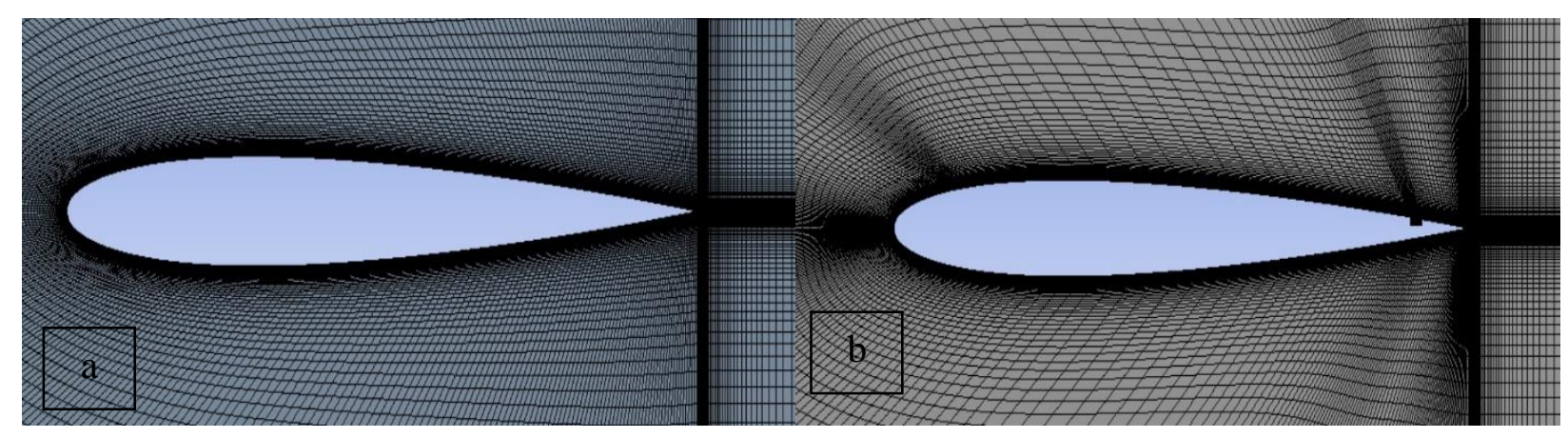

Figure 2. Grids of a) baseline airfoil b) airfoil with suction and cavity

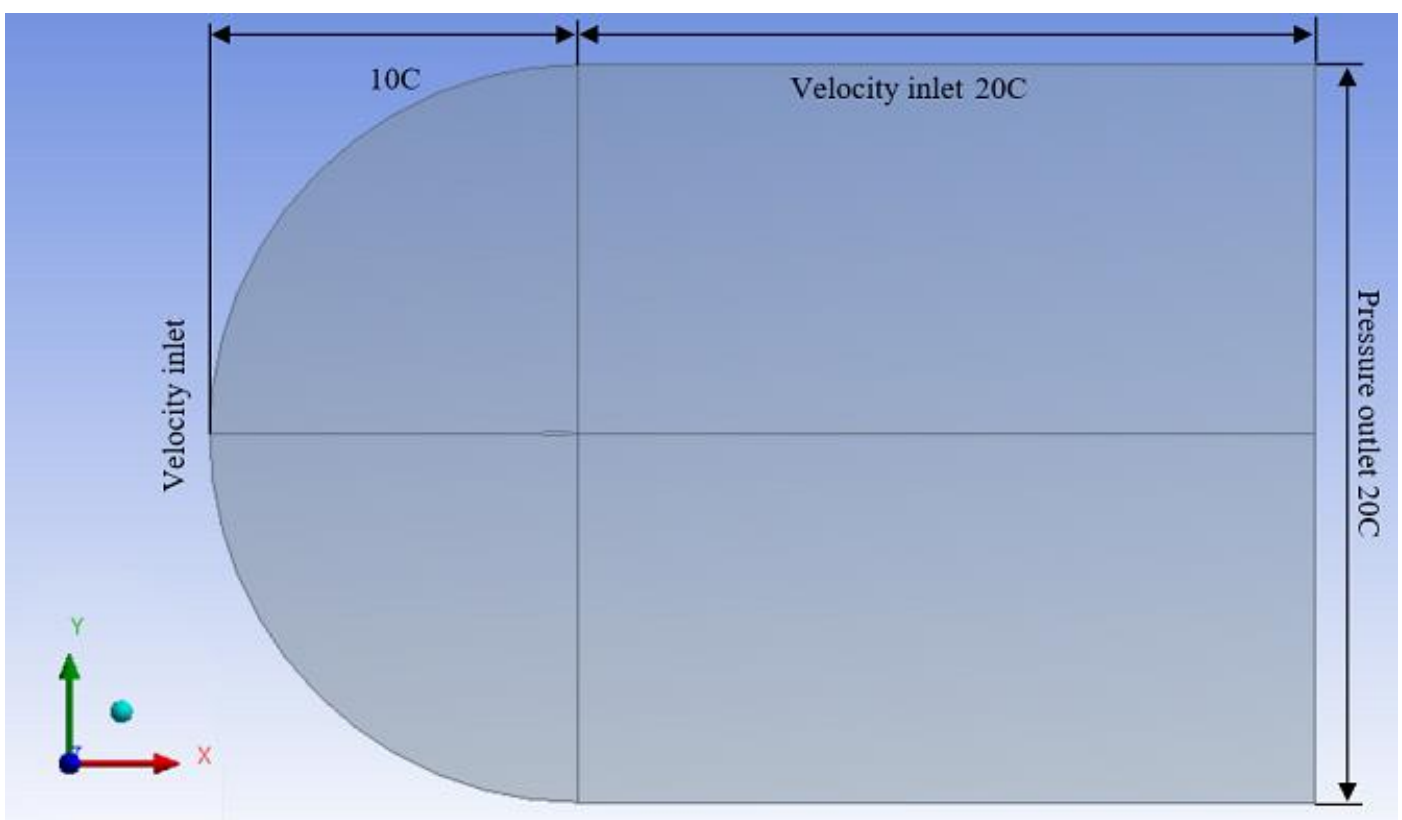

Figure 3. Boundary condition 


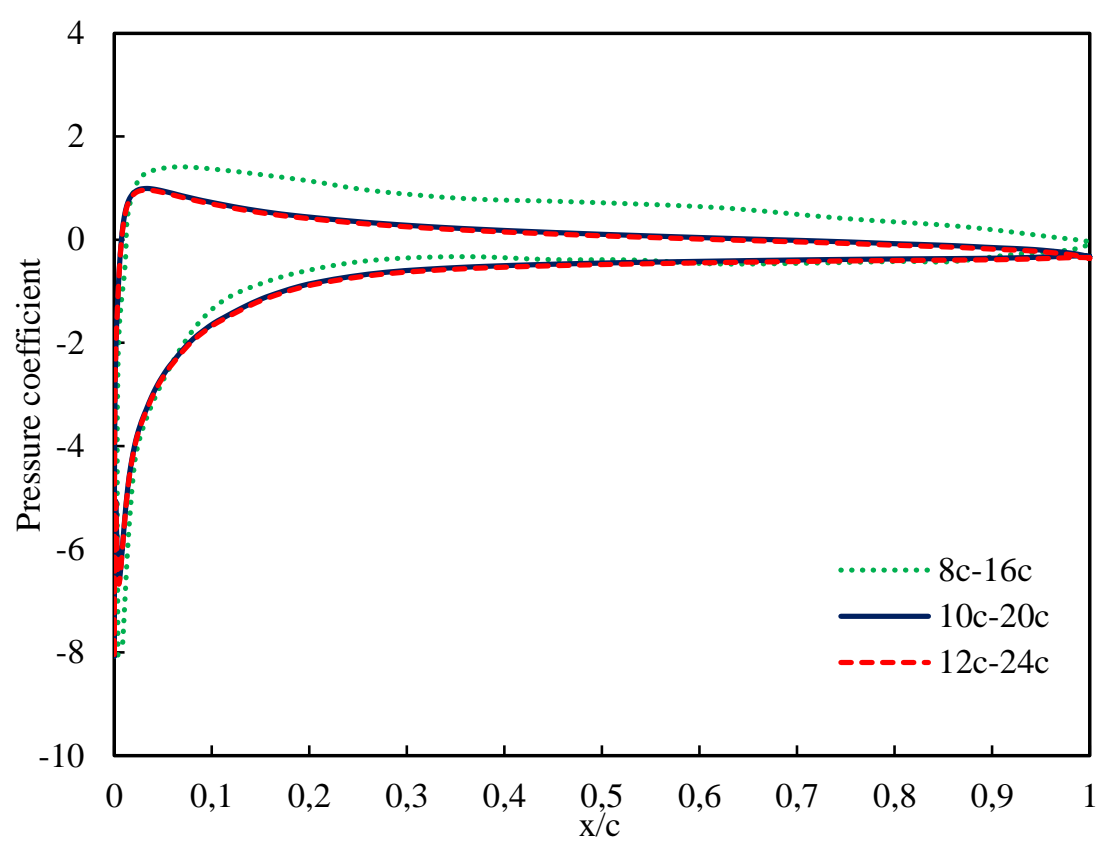

Figure 4. Domain extent independence test results

\section{NUMERICAL PROCEDURE}

The fluid flow is considered as unsteady, 2D turbulent, and incompressible. URANS equations are as follows [37]:

$\frac{\partial}{\partial x_{i}}\left(u_{i}\right)=0$

$\rho \frac{\partial}{\partial t}\left(u_{i}\right)+\rho \frac{\partial}{\partial x_{j}}\left(u_{i} u_{j}\right)=-\frac{\partial P}{\partial x_{i}}+\mu \frac{\partial}{\partial x_{j}}\left(\frac{\partial u_{i}}{\partial x_{j}}\right)+\frac{\partial}{\partial x_{j}}\left(-\rho\left\langle u_{j}^{\prime} u_{i}^{\prime}\right\rangle\right)$

where $u$ denotes the ensemble-averaged velocity. $P, \mu$, and $\rho$ represent the ensemble-averaged pressures, viscosity, and density, respectively.

Furtheremore, URANS equations are solved with SST k- $\omega$ turbulence model. As mentioned in previous researches $[14,22,33]$ of similar flows, SST k- $\omega$ demonstrates the good predictive capability for flow having separation which can be written as follows [38]:

$$
\begin{aligned}
& \frac{\partial}{\partial t}(\rho k)+\frac{\partial}{\partial x_{i}}\left(\rho k u_{i}\right)=\frac{\partial}{\partial x_{j}}\left[\Gamma_{k} \frac{\partial k}{\partial x_{j}}\right]+G_{k}-Y_{k} \\
& \frac{\partial}{\partial t}(\rho \omega)+\frac{\partial}{\partial x_{i}}\left(\rho \omega u_{i}\right)=\frac{\partial}{\partial x_{j}}\left[\Gamma_{\omega} \frac{\partial \omega}{\partial x_{j}}\right]+G_{\omega}-Y_{\omega}+D_{\omega} .
\end{aligned}
$$

The simulations are done with commercial software Ansys Fluent v18.2. The flow simulations are implemented on NACA 0012 airfoil with 1 meter chord length which has a Reynolds number equal to $5 \times 10^{5}$. Also, the SIMPLE coupled algorithm is utilized for pressure-velocity coupling and the second-order upwind scheme is applied for the discretization of the governing equation. The time step in the simulation 
process is equal to $1 \times 10^{-4}$ to attain the CFL number $<1$. Numerical results are converged as the scaled residual is gained less than $1 \times 10^{-6}$ and also for all the computations, $\mathrm{y}^{+}<1$.

In this study, for different angles of attack $(\alpha)$, three parameters including jet location which is located at $10 \%$ of airfoil chord length $\left(\mathrm{L}_{\mathrm{jet}}=0.1 \mathrm{c}\right)$, jet velocity ratio $\left(\mathrm{R}_{\mathrm{jet}}=0.15\right)$, and jet angle $\left(\theta_{\text {jet }}=-90^{\circ}\right)$ are used to computationally analyzed the impact of perpendicular suction (Figure 5). On upper surface of the airfoil, the suction jet with a width of $0.25 \mathrm{c}$ is located as demonstrated by Dannenberg and Weiberg [39]. Besides, the cavity is located at $0.9 \mathrm{c}$ and has a width and depth equal to $20 \mathrm{~mm}$ and $10 \mathrm{~mm}$, respectively. Inlet velocity is set as a boundary condition to apply suction jet. The jet entrance velocity can be written as [32]:

$$
\begin{aligned}
& R_{j e t}=\frac{U_{j e t}}{U_{\infty}} \\
& u=U_{j e t} \cos \left(\theta_{j e t}+\beta\right) \\
& v=U_{j e t} \sin \left(\theta_{j e t}+\beta\right) .
\end{aligned}
$$

In these equations, $\theta_{\text {jet }}$ denotes the angle between the local jet surface and jet entrance velocity direction $[12,32] . \mathrm{U}_{\infty}(7.3 \mathrm{~m} / \mathrm{s})$ indicates the free stream velocity and $\beta$ represents the angle between freestream velocity direction and the local jet surface. The values of Beta changes with the angles of attack $(\alpha)$, whereas it is equal to $7^{\circ}$ at $\alpha=14^{\circ}$.

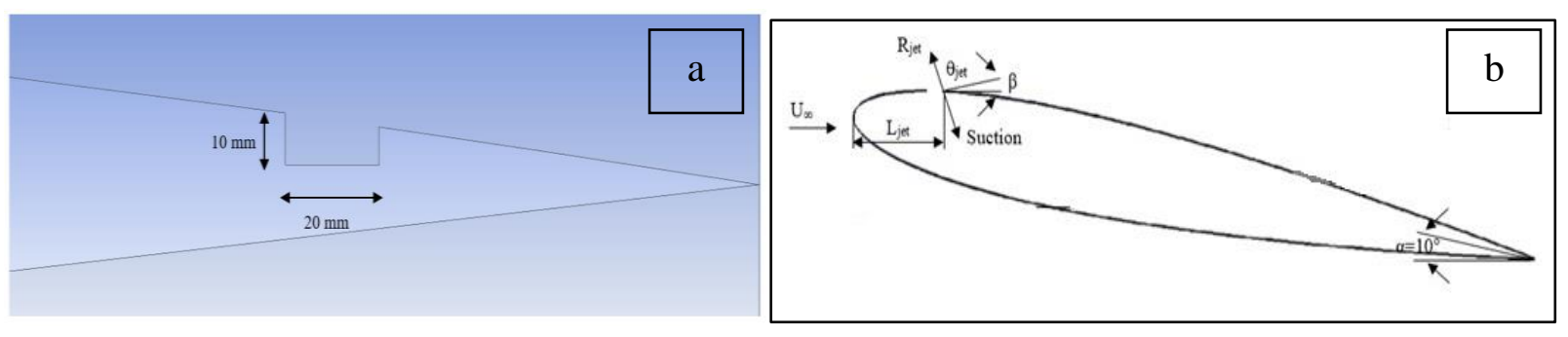

Figure 5. The schematic of airfoil with a) cavity and b) suction

\section{GRID AND TIME INDEPENDENCE STUDIES}

The details of grid cell and $y^{+}$distribution are provided in Table 1 at $\alpha=10^{\circ}$ and $\operatorname{Re}=5 \times 10^{5}$. In this study, a grid independence study is conducted for different cell numbers including 41000, 53000, 65000, and 77000 by investigating the drag and lift coefficients over the airfoil (Figures 6 and 7). The grid size with a grid-independent result has 65000 cells which are demonstrated a reasonable accuracy.

Table 1. Cell numbers and $y^{+}$distribution

\begin{tabular}{ccccccc}
\hline Grid & Cell numbers & $\begin{array}{c}\text { Growth } \\
\text { factor }\end{array}$ & First cell (Height) & $\mathrm{y}^{+}($Max $)$ & $\mathrm{y}^{+}($Min) & $\begin{array}{c}\mathrm{y}^{+} \\
\text {(Average) }\end{array}$ \\
\hline 1 & 41000 & 1.1 & $1 \times 10^{-3}$ & 7.63 & 4.04 & 2.43 \\
2 & 53000 & 1.1 & $1 \times 10^{-4}$ & 4.46 & 1.58 & 2.86
\end{tabular}




\begin{tabular}{rrrrrrr}
3 & 65000 & 1.1 & $1 \times 10^{-5}$ & 0.88 & 0.07 & 0.45 \\
4 & 77000 & 1.1 & $5 \times 10^{-6}$ & 0.73 & 0.03 & 0.29 \\
\hline
\end{tabular}

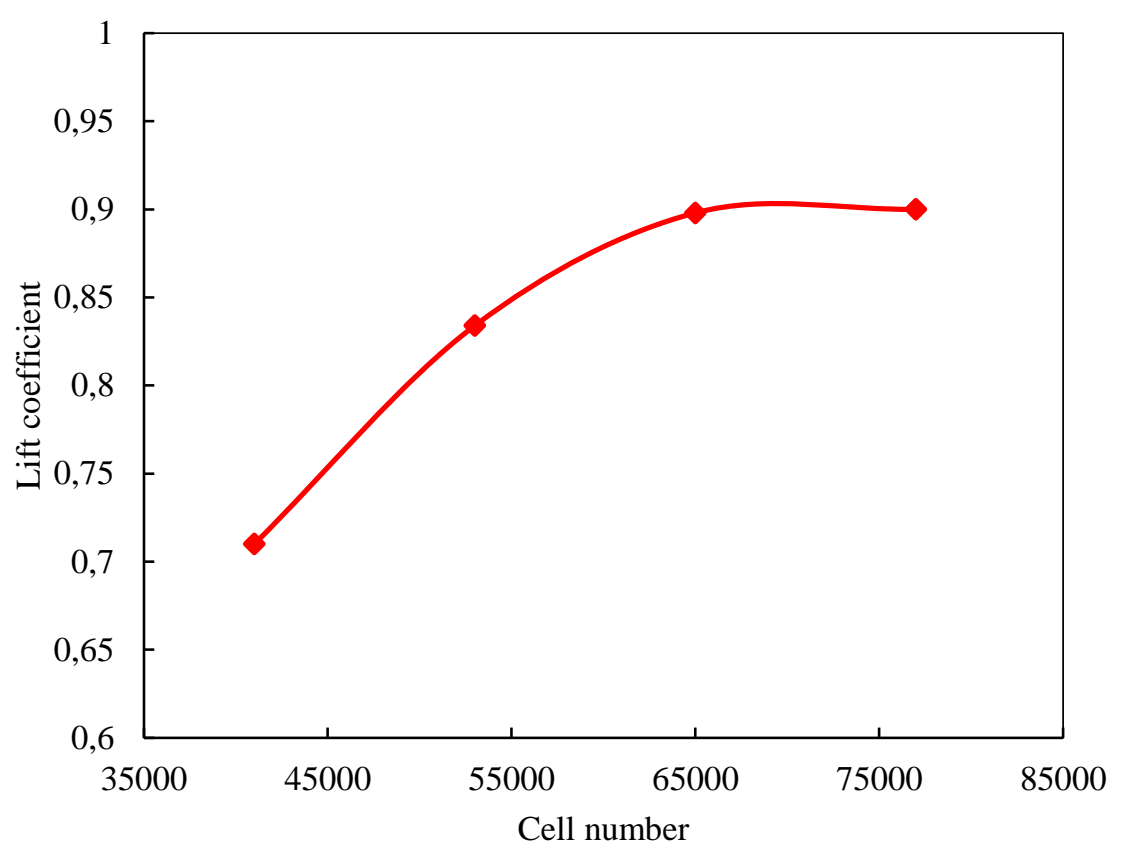

Figure 6. Grid independence study for lift coefficient at $\alpha=10^{\circ}$

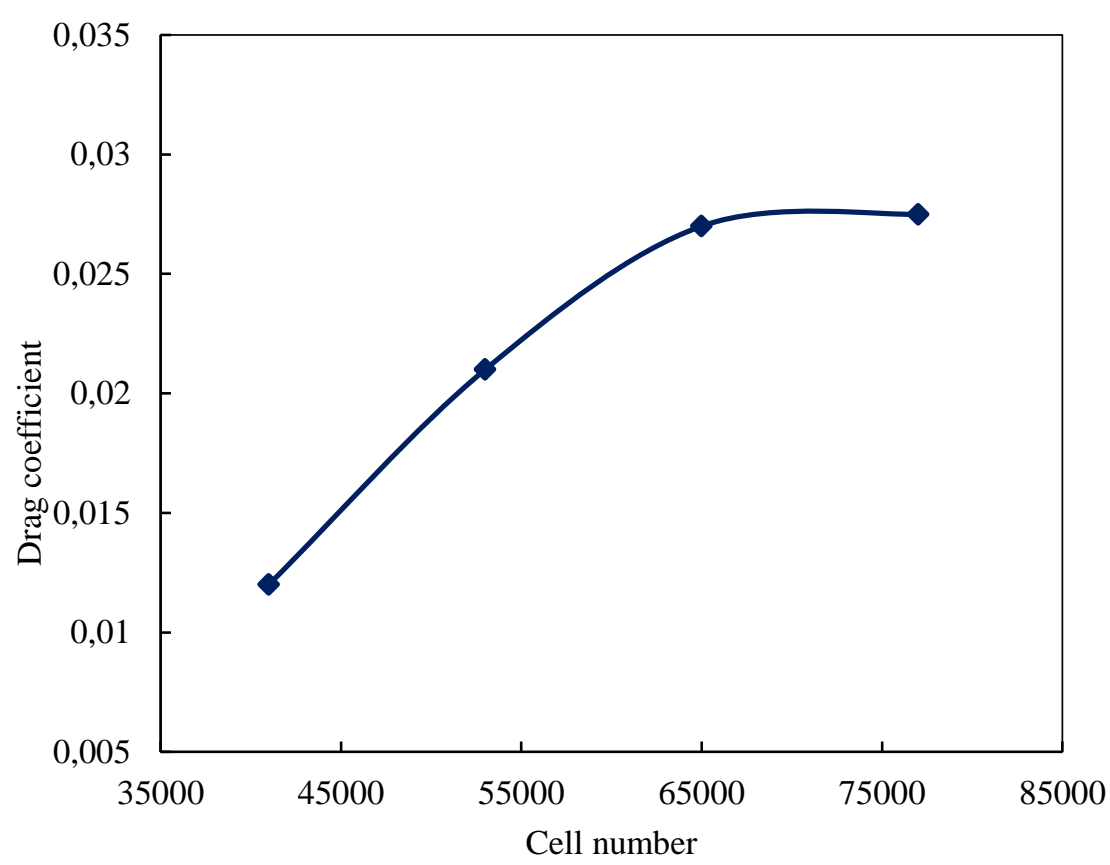

Figure 7. Grid independence study for drag coefficient $\alpha=10^{\circ}$

Moreover, an independence study for time step is performed to show the reliability of solution (Table 2). Hence, 4 different time steps are selected for comparing lift coefficient and drag coefficient in the case of suction and cavity at $\alpha=14^{\circ}$. Finally, it is concluded that the $1 \times 10^{-4}$ (time step) is reasonable for the present study. 
Table 2. An independence study for time step at $\alpha=14^{\circ}$

\begin{tabular}{ccc}
\hline $\mathrm{C}_{\mathrm{L}}$ & $\mathrm{C}_{\mathrm{D}}$ & Time step (second) \\
\hline 1.428 & 0.179 & $1 \times 10^{-3}$ \\
1.194 & 0.136 & $5 \times 10^{-4}$ \\
1.023 & 0.108 & $1 \times 10^{-4}$ \\
1.022 & 0.107 & $1 \times 10^{-5}$ \\
\hline
\end{tabular}

In Figure 8, time histories of lift coefficient and drag coefficient are presented in Figure 8 for without suction and cavity case at $\alpha=14^{\circ}$. It is obvious that time history of these coefficients are repeated in a periodic way. The average values of lift coefficient and drag coefficient are used for further analysis throughout the present numerical study.
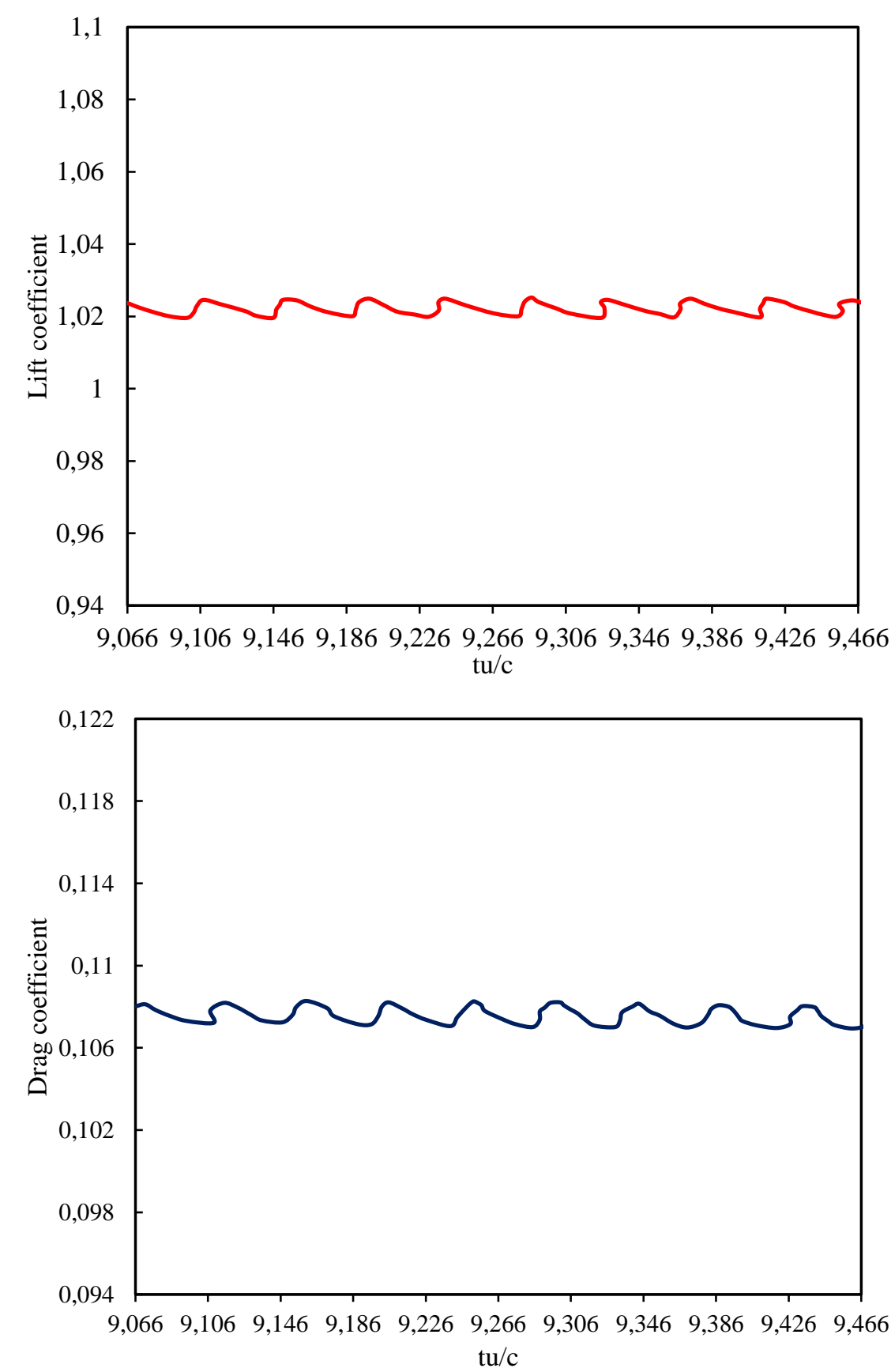

Figure 8. Time histories of lift coefficient and drag coefficient for without suction and cavity case at $\alpha=$ $14^{\circ}$ 


\section{VALIDATION SECTION}

The numerical results of drag and lift coefficients in terms of angles of attack for without suction and cavity case are compared with the results of Huang et al. [12] and Yousefi et al. [33] and the available experimental results of Critzos et al. [40], Jacobs et al. [41] all at a Reynolds number of $5 \times 10^{5}$. Good agreement is seen between computational results and reported studies as shown in Figure 9. The difference between the values in higher angle of attacks can be due to turbulence models, artificial viscosities, grid density, and limitation of 2D simulation which can produce computational inaccuracy.
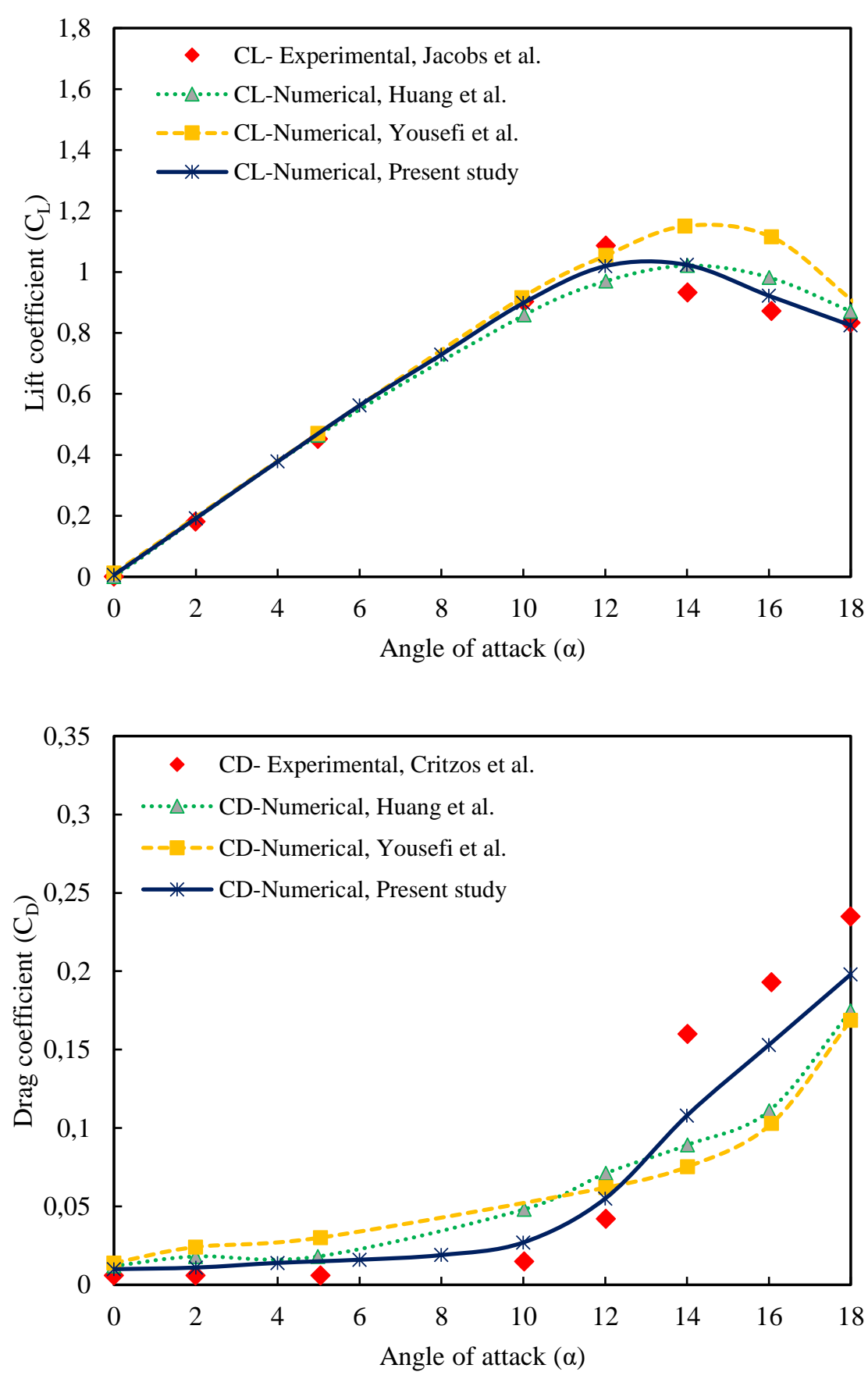

Figure 9. Validation 


\section{RESULTS AND DISCUSSION}

The effect of simultaneous cavity and suction on lift and drag coefficients in terms of $\alpha$ is depicted in Figures 10 and 11. In suction case, the low energy fluid existed in boundary layer is eliminated through suction jet and removes its losses [42]. The suction jet location $\left(\mathrm{L}_{\mathrm{jet}}\right)$ is placed at $0.1 \mathrm{c}$ which is reported in previous works [6,12]. Therefore, a perpendicular suction jet is used with $\theta_{\text {jet }}=-90^{\circ}$ and $R_{\text {jet }}=0.15$ which is located at $\mathrm{L}_{\mathrm{jet}}=0.1$, and a cavity is simultaneously utilized at $(0.9 \mathrm{c})$ with $20 \mathrm{~mm}$ width and $10 \mathrm{~mm}$ depth. It can be concluded that the simultaneous use of suction and cavity has a notable impact on increasing aerodynamic performance resulting in an increase in stall angle $\left(14^{\circ}\right.$ to $\left.22^{\circ}\right)$. Also, there is a significant increase in lift coefficient and drag coefficient by utilizing this flow control method. $\mathrm{C}_{\mathrm{L}}$ is enhanced by approximately $30 \%$ and the drag coefficient $\left(C_{D}\right)$ is reduced approximately $43 \%$ with the simultaneous use of suction and cavity at $\alpha=14^{\circ}$.

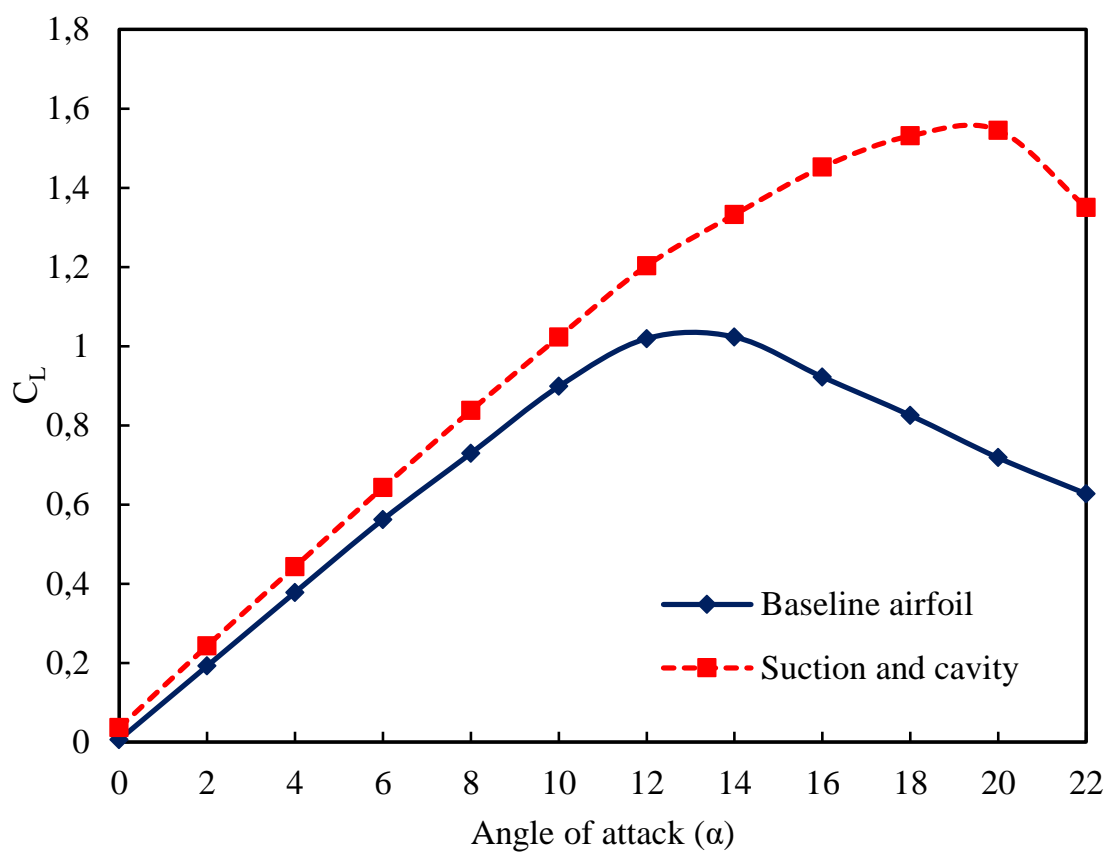

Figure 10. Changes in lift coefficient 


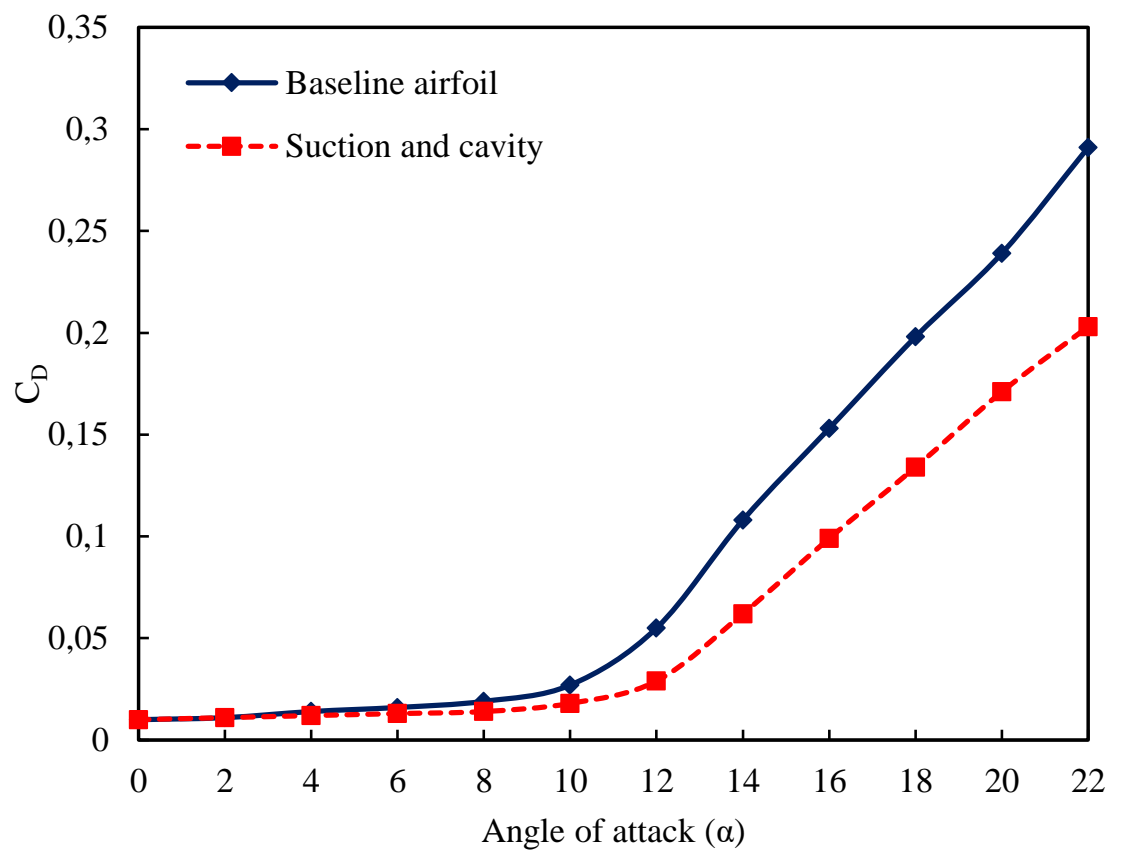

Figure 11. Changes in drag coefficient

Furthermore, lift to drag ratio $\left(\mathrm{C}_{\mathrm{L}} / \mathrm{C}_{\mathrm{D}}\right)$ is numerically analyzed to further consideration of the effect of simultaneous use of suction and cavity (Figure 12). As it can be seen, the simultaneous use of suction and cavity increased $C_{L} / C_{D}$, and the highest value of increment in $C_{L} / C_{D}$ is obtained at $\alpha=8^{\circ}$ which is 1.6 times higher than the baseline airfoil. Figure 13 depicts the pressure coefficient $\left(\mathrm{C}_{\mathrm{p}}\right)$ for baseline airfoil and simultaneous suction and cavity case at $\alpha=14^{\circ}$. By considering these cases, it was found that sudden changes in pressure coefficient have been observed at the suction slot location, which has a positive impact on improving aerodynamic coefficients.

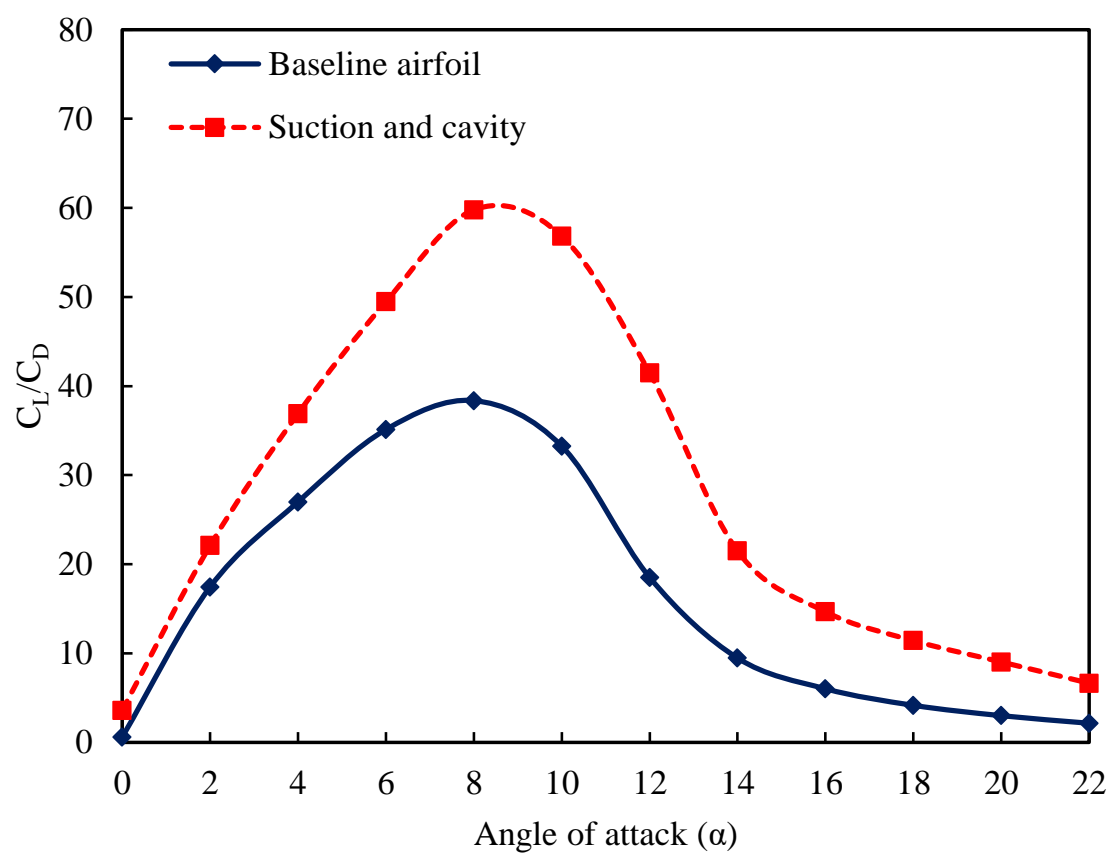

Figure 12. Changes of $C_{L} / C_{D}$ for baseline airfoil and airfoil with suction and cavity cases 


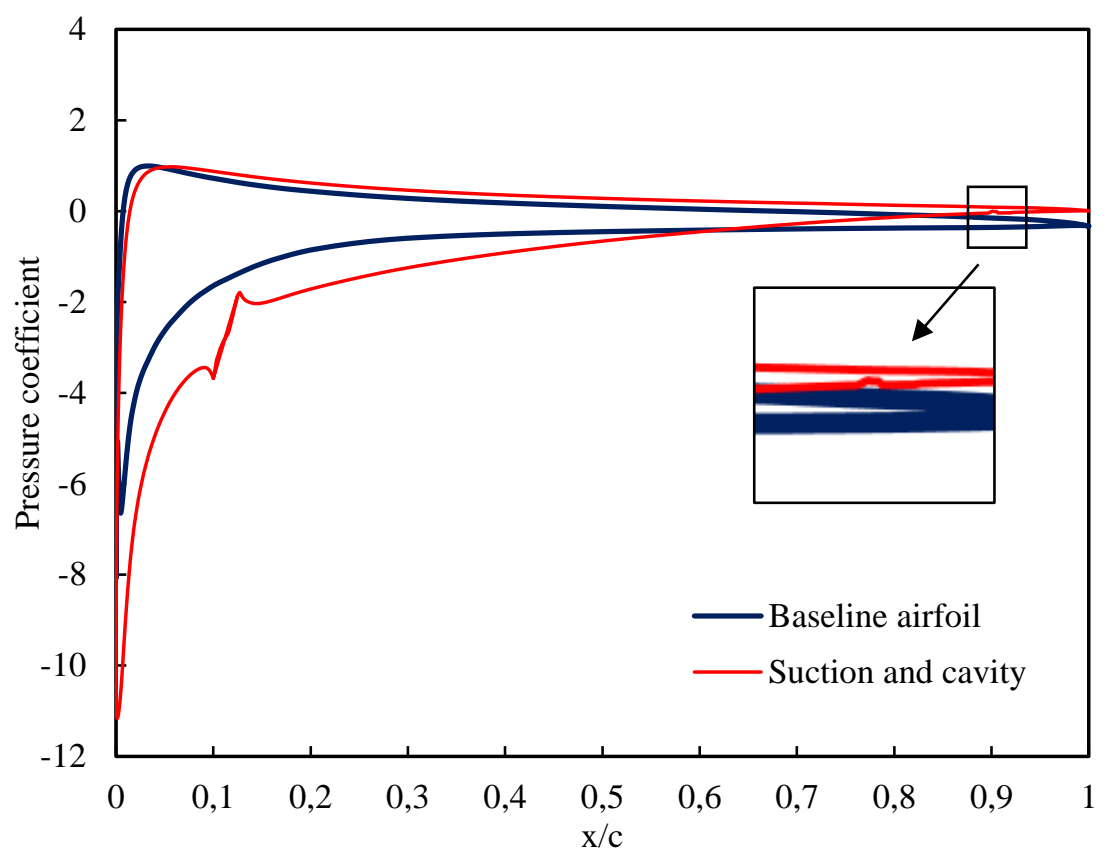

Figure 13. The pressure coefficient $\left(C_{p}\right)$ for baseline airfoil and airfoil with suction and cavity cases

Figure 14 indicates the velocity field contours of the NACA 0012 airfoil for simultaneous suction and cavity case and without suction case at $\alpha=14^{\circ}$. When the boundary layer separates, the drag will increase, and also causes to increase in lift and finally stall occurs. The main application of suction is to eliminate lowenergy boundary layer which causes to postpone the flow separation [42]. Naturally, the cavity causes to form the vortices which lead to induce the flow reattachment, therefore requiring no additional energy expenditure [30]. The vortices trapped in cavity could re-energize boundary layer thus maintained flow attachment downstream of the cavity and delay flow separation [30]. Hence, the flow control jet including simultaneous suction and cavity shows a considerable effect on postponing and controlling the flow separation. Moreover, the recirculation zone has gone downstream and completely eliminated by utilizing the mentioned flow control method. Figure 15 illustrates the pressure field (Pa) around the airfoil for simultaneous suction and cavity case and without suction case at $\alpha=14^{\circ}$. The pressure is reduced on airfoil upper surface and this results in higher velocity and momentum on the upper surface. It eventually delays the flow separation by applying the flow control method. 

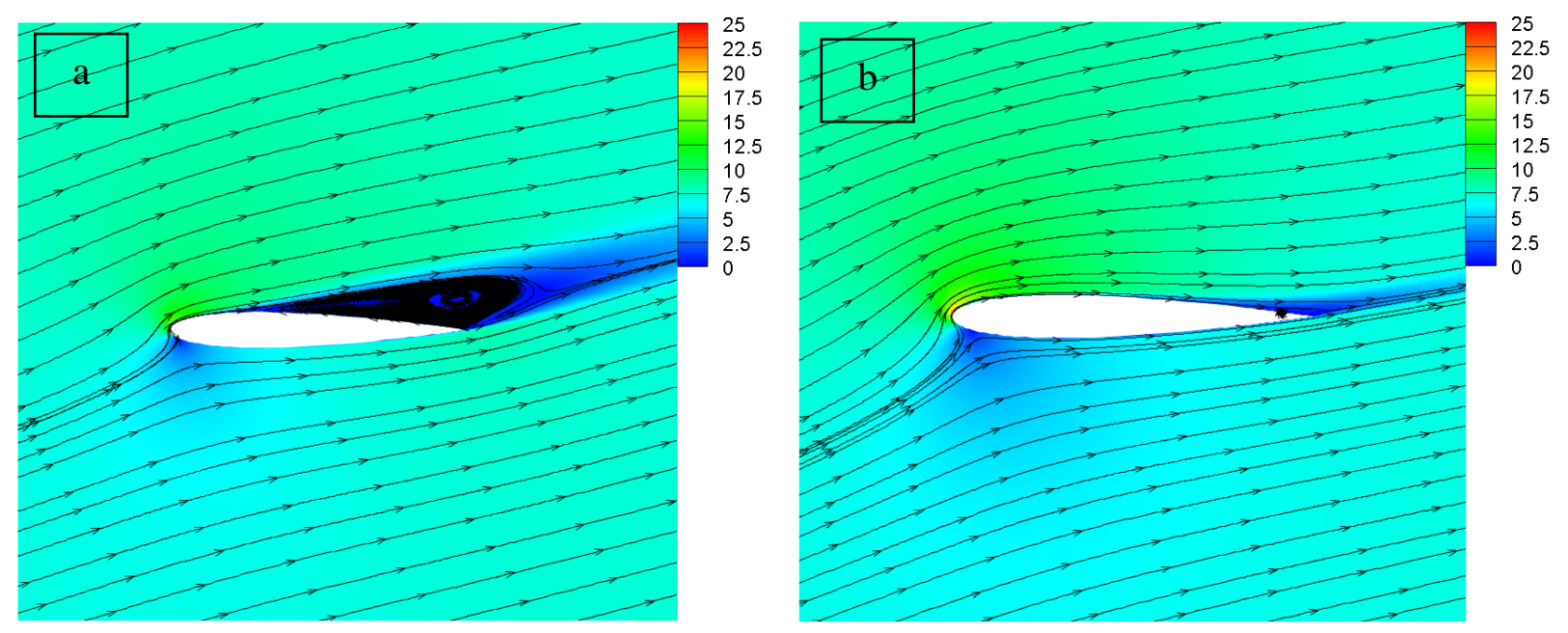

Figure 14. The velocity field $(\mathrm{m} / \mathrm{s})$ contours for a) baseline airfoil and b) simultaneous suction and cavity case
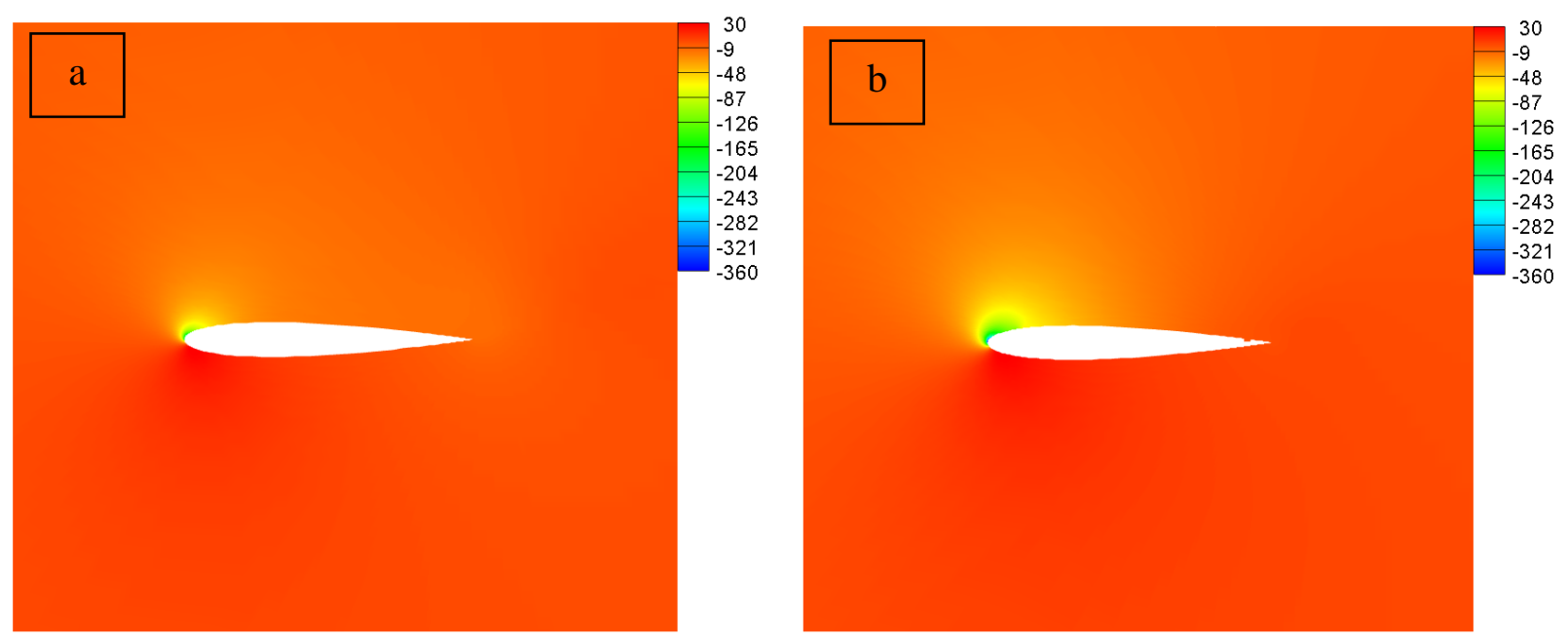

Figure 15. The pressure field ( $\mathrm{Pa}$ ) around NACA 0012 airfoil for a) without suction and cavity case and b) simultaneous suction and cavity case

\section{CONCLUSION}

In this work, a CFD-based analysis is conducted to examine simultaneous effect of suction and cavity on controlling flow separation over NACA 0012 airfoil. The numerical simulation is carried out utilizing Ansys Fluent v18.2. A perpendicular suction jet $\left(\theta_{\text {jet }}=-90^{\circ}\right)$ is applied at $L_{\text {jet }}=0.1$ and a cavity is simultaneously used at $0.9 \mathrm{c}$. Based on the numerical results, the simultaneous use of suction and cavity has a significant effect on the enhancement of aerodynamic performance which leads to improve stall angle from $14^{\circ}$ to $22^{\circ}$. Besides, lift coefficient has enhanced by $30 \%$ and drag coefficient has decreased by $40 \%$ through simultaneous suction and cavity at $\alpha=14^{\circ}$. The flow control method improves lift to drag ratio and the highest value of increment in $\mathrm{C}_{\mathrm{L}} / \mathrm{C}_{\mathrm{D}}$ is obtained at $\alpha=8^{\circ}$. Consequently, the simultaneous suction and cavity have a great impact on delaying the flow separation. Also, the recirculation zone has gone downstream and completely eliminated. 


\section{CONFLICTS OF INTEREST}

No conflict of interest was declared by the authors.

\section{REFERENCES}

[1] Fatahian, E., Salarian, H., Fatahian, H., "Numerical investigation of hazardous gas dispersion over obstacles and residential Areas", International Journal of Engineering, 33(10): 2087-2094, (2020).

[2] Ahangar, S. B., Bellur, K., Medici, E., Tajiri, K., Allen, J. S., Choi, C. K., "Optical properties and swelling of thin film perfluorinated sulfonic-acid ionomer", ECS Transactions, 92(8): 197-212, (2019).

[3] Siala, F. F., Kamrani Fard, K., Liburdy, J. A., "Experimental study of inertia-based passive flexibility of a heaving and pitching airfoil operating in the energy harvesting regime", Physics of Fluids, 32(1): 017101, (2020).

[4] Fatahian, H., Hosseini, E., Fatahian, E., "CFD simulation of a novel design of square cyclone with dual-inverse cone”, Advanced Powder Technology, 31(4): 1748-1758, (2020).

[5] Bayaniahangar, R., Ahangar, S. B., Zhang, Z., Lee, B. P., Pearce, J. M., "3-D printed soft magnetic helical coil actuators of iron oxide embedded polydimethylsiloxane", Sensors and Actuators B: Chemical, 326: 128781, (2021).

[6] Monir, H. E., Tadjfar, M., Bakhtian, A., "Tangential synthetic jets for separation control”, Journal of fluids and structures, 45: 50-65, (2014).

[7] Fatahian, E., Nichkoohi, A. L., Salarian, H., Khaleghinia, J., "The effect of suction jet angle on aerodynamic performance of NACA 0012 flapped airfoil-a CFD approach", 4th International Conference on Applied researches in Science and Engineering, Vrije Universiteit Brussel, Belgium, (2019).

[8] Fatahian, H., Salarian, H., Eshagh Nimvari, M., Khaleghinia, J., "Numerical simulation of the effect of rain on aerodynamic performance and aeroacoustic mechanism of an airfoil via a twophase flow approach", SN Applied Sciences, 2: 1-16, (2020).

[9] Wei, B., Wu, Y., Liang, H., Su, Z., Li, Y., "Flow control on a high-lift wing with microsecond pulsed surface dielectric barrier discharge actuator", Aerospace Science and Technology, 96: 1-20, (2020).

[10] Lei, J., Zhang, J., Niu, J., "Effect of active oscillation of local surface on the performance of low Reynolds number airfoil”, Aerospace Science and Technology, 99: 25-40, (2020).

[11] Fatahian, E., Nichkoohi, A. L., Fatahian, H., "Numerical study of the effect of suction at a compressible and high Reynolds number flow to control the flow separation over Naca 2415 airfoil", Progress in Computational Fluid Dynamics, an International Journal, 19(3): 170-179, (2019).

[12] Huang, L., Huang, P. G., LeBeau, R. P., Hauser, T., "Numerical study of blowing and suction control mechanism on NACA 0012 airfoil", Journal of aircraft, 41(5): 1005-1013, (2004). 
[13] Fatahian, H., Salarian, H., Nimvari, M. E., Fatahian, E., "Numerical study of suction and blowing approaches to control flow over a compressor cascade in turbulent flow regime", International Journal of Automotive and Mechanical Engineering, 15(2): 1-18, (2018).

[14] Fatahian, E., Nichkoohi, A. L., Salarian, H., Khaleghinia, J., "Effects of the hinge position and suction on flow separation and aerodynamic performance of the NACA 0012 airfoil", Journal of the Brazilian Society of Mechanical Sciences and Engineering, 42(2): 1-14, (2020).

[15] Tadjfar, M., Kamari, D., "Optimization of Flow Control Parameters Over SD7003 Airfoil with Synthetic Jet Actuator", Journal of Fluids Engineering, 142(2):1-22, (2020).

[16] Kim, S. H., Kim, C., "Separation control on NACA 23012 using synthetic jet", Aerospace Science and Technology, 13(4): 172-182, (2009).

[17] Monastero, M. C., Lindstrom, A. M., Amitay, M., "Effect of Synthetic Jets Spacing on Flow Separation over Swept, Flapped Airfoils", AIAA Journal, 57(11): 4670-4683, (2019).

[18] Fatahian, E., Nichkoohi, A. L., Salarian, H., Khaleghinia, J., "Comparative study of flow separation control using suction and blowing over an airfoil with/without flap", Sadhana, 44(11): 220-235, (2019).

[19] Fatahian, H., Salarian, H., Nimvari, M. E., Khaleghinia, J., "Computational fluid dynamics simulation of aerodynamic performance and flow separation by single element and slatted airfoils under rainfall conditions", Applied Mathematical Modelling, 83: 683-702, (2020).

[20] Li, Y., Wang, J., Zhang, P., "Effects of Gurney flaps on a NACA 0012 airfoil”, Flow, Turbulence and Combustion, 68(1): 27-40, (2002).

[21] Storms, B. L., Jang, C. S., "Lift enhancement of an airfoil using a Gurney flap and vortex generators", Journal of Aircraft, 31(3): 542-547, (1994).

[22] Hao, W., Ding, Q., Li, C., "Optimal performance of adaptive flap on flow separation control”, Computers \& Fluids, 179: 437-448, (2019).

[23] Fatahian, H., Salarian, H., Nimvari, M. E., Khaleghinia, J., "Effect of Gurney flap on flow separation and aerodynamic performance of an airfoil under rain and icing conditions", Acta Mechanica Sinica, 37: 1-19, (2020).

[24] James, S. E., Suryan, A., Sebastian, J. J., Mohan, A., Kim, H. D., "Comparative study of boundary layer control around an ordinary airfoil and a high lift airfoil with secondary blowing", Computers \& Fluids, 164: 50-63, (2018).

[25] Bunyakin, A. V., "Laminar boundary layer in a flow past an aerofoil with a circular cavity", Fluid dynamics, 33(2): 196-200, (1998).

[26] Vuddagiri, A., Samad, A., "Vortex trapping by different cavities on an airfoil", Wind Engineering, 37(5): 469-482, (2013).

[27] Olsman, W. F. J., Colonius, T., "Numerical simulation of flow over an airfoil with a cavity", AIAA Journal, 49(1): 143-149, (2011).

[28] Chernyshenko, S. I., Galletti, B., Iollo, A., Zannetti, L., "Trapped vortices and a favourable pressure gradient", Journal of Fluid Mechanics, 482: 235-255, (2003). 
[29] De Gregorio, F., Fraioli, G., "Flow control on a high thickness airfoil by a trapped vortex cavity", In 14th International symposium on applications of laser techniques to fluid mechanics, Lisbon, Portugal, (2008).

[30] Vuddagiri, A., Halder, P., Samad, A., Chaudhuri, A., "Flow analysis of airfoil having different cavities on its suction surface", Progress in Computational Fluid Dynamics, an International Journal, 16(2): 67-77, (2016).

[31] Ma, D., Li, G., Yang, M., Wang, S., "Research of the suction flow control on wings at low Reynolds numbers", Proceedings of the Institution of Mechanical Engineers, Part G: Journal of Aerospace Engineering, 232(8): 1515-1528, (2018).

[32] Genç, M. S., Kaynak, Ü., Yapici, H., "Performance of transition model for predicting low Re aerofoil flows without/with single and simultaneous blowing and suction", European Journal of Mechanics-B/Fluids, 30(2): 218-235, (2011).

[33] Yousefi, K., Saleh, R., Zahedi, P., "Numerical study of blowing and suction slot geometry optimization on NACA 0012 airfoil", Journal of Mechanical Science and Technology, 28(4): 12971310, (2014).

[34] Zhang, W., Zhang, Z., Chen, Z., Tang, Q., "Main characteristics of suction control of flow separation of an airfoil at low Reynolds numbers", European Journal of Mechanics-B/Fluids, 65: 88-97, (2017).

[35] Lei, J., Liu, Q., \& Li, T., "Suction control of laminar separation bubble over an airfoil at low Reynolds number", Proceedings of the Institution of Mechanical Engineers, Part G: Journal of Aerospace Engineering, 233(1): 81-90, (2019).

[36] Zhou, Y., Hou, L., Huang, D., "The effects of Mach number on the flow separation control of airfoil with a small plate near the leading edge", Computers \& Fluids, 156: 274-282, (2017).

[37] Ockfen, A. E., Matveev, K. I., "Aerodynamic characteristics of NACA 4412 airfoil section with flap", International Journal of Naval Architecture and Ocean Engineering, 1(1): 1-12, (2009).

[38] Menter, F. R., "Two-equation eddy-viscosity turbulence models for engineering applications", AIAA Journal, 32(8): 1598-1605, (1994).

[39] Dannenberg, R. E., Weiberg, J. A., "Section characteristics of a 10.5-percent-thick airfoil with area suction as affected by chordwise distribution of permeability", NASA TN 2847, (1952).

[40] Critzos, C. C., Heyson, H. H., Boswinkle Jr, R. W., "Aerodynamic characteristics of NACA 0012 airfoil section at angles of attack from 0 deg to 180 deg", No. NACA-TN-3361, National Aeronautics and Space Administration, Washington, (1955).

[41] Jacobs, E. N., Sherman, A., "Airfoil section characteristics as affected by variations of the Reynolds number”, NACA report, 586: 227-264, (1937).

[42] Schlichting, H., Gersten, K., "Boundary-layer control (suction/blowing)", In Boundary-Layer Theory, Springer, Berlin, Heidelberg, (2000).

[43] Mazaheri, K., Nejati, A., Charlang Kiani, K., "The application of suction and blowing in performance improvement of transonic airfoils with shock control bump", Scientia Iranica, 24(1): 274-292, (2017). 